\title{
RANTAI PASOK DAN NILAI TAMBAH KERIPIK NANGKA PADA AGROINDUSTRI KERIPIK PANDA ALAMI DI KECAMATAN GEDONG TATAAN KABUPATEN PESAWARAN
}

\author{
(Supply Chain and Added Value of Jackfruits Chips in Chips Agroindustry of Panda Alami in Gedong \\ Tataan Sub-district, Pesawaran District)
}

\author{
Rini Yunita Sari, Ali Ibrahim Hasyim, Sudarma Widjaya \\ Jurusan Agribisnis, Fakultas Pertanian, Universitas Lampung, Jl. Prof. Dr. Soemantri Brodjonegoro No. 1 \\ Bandar Lampung 35145, Telp. 082280244687, email: riniyunitass27@ yahoo.com
}

\begin{abstract}
This study aims to analyze the flow pattern of supply chain of jackfruits, supply chain performance, supply chain efficiency, and calculate the added value products of Jackfruits chip in Panda Alami Agroindustry. This study is conducted purposely in Panda Alami Agroindustry in Gedong Tataan Sub-district of Pesawaran District. The data is collected in Februari 2017, performance measurements are made by comparing measurement indicators with FoodSCOR Card indicators. Efficiency calculations are performed using a software deap 2.1, the calculation of value added is done by Hayami added value method. The result showed that the flow pattern starting from the farmers as the main raw material supplier. The performance of the supplier of Panda Alami Agroindustry was good, based on compared value of FoodSCOR card. Efficiency measurements indicated that only 37.5 percent of supply chain actors were already efficient for DMU farmers' category, and 100 percent efficient for retail and agroindustry category. The calculation of the added value of jackfruits chips of Panda Alami Agroindustry showed positive value, it meant that agroindustry was feasible to be developed.
\end{abstract}

Key words: added value, agroindustry, efficiency, farmers, jackfruits, performance.

\section{PENDAHULUAN}

Agroindustri keripik Panda Alami berada di Desa Cipadang Kecamatan Gedong Tataan Kabupaten Pesawaran. Usaha ini telah berdiri sejak tahun 1998, agroindustri ini termasuk yang terbesar di Kabupaten Pesawaran dilihat dari kapasitas bahan baku yang diolah yaitu sebesar $2.500 \mathrm{~kg}$ per hari. Awalnya agroindustri ini hanya mengolah keripik pisang, namun sejalan dengan meningkatnya permintaan berbagai makanan berbahan baku produk pertanian, maka agroindustri Panda Alami melakukan pengembangan produk yaitu keripik nangka.

Permintaan keripik nangka Panda Alami terus mengalami peningkatan. Dalam pemenuhan permintaan tersebut agroindustri di hadapkan kepada keterbatasan bahan baku nangka, pengadaan bahan baku nangka relatif masih sulit karena pola produksi nangka yang masih bersifat sporadik dan belum menjadi usahatani utama. Selama ini CV Panda Alami memperoleh bahan baku nangka dari petani dan produk yang dihasilkan Panda Alami dipasarkan melalui pedagang dan secara langsung kepada konsumen. Dengan demikian, usaha Panda Alami berkembang dengan melibatkan berbagai unit-unit pengambi keputusan baik yang bergerak pada aliran bahan baku maupun pada produk hasil olahan yang secara keseluruhan terancang dalam sebuah sistem rantai pasok, sehingga perlu dilakukan pengukuran kinerja untuk mengevaluasi apakah tujuan akhir agroindustri telah tercapai atau belum tercapai.

Pada penelitian ini akan dihitung pula efisiensi rantai pasok pada Agroindustri Keripik Panda Alami untuk mengetahui DMU (Decision Making Unit) mana yang belum efisien, sehingga dapat ditinjau untuk mencapai tingkat efisien. Pengolahan keripik nangka merupakan pengelolaan bahan mentah yang akan ditransformasikan menjadi barang siap digunakan, sehingga perhitungan nilai tambah juga perlu dilakukan untuk mengetahui nilai tambah yang dihasilkan oleh masing-masing produk.

Berdasarkan penjelasan yang telah dijabarkan di atas, tujuan dari penelitian ini adalah untuk mengetahui pola aliran rantai pasok komoditas nangka pada Agroindustri Keripik Panda Alami di Kecamatan Gedong Tataan Kabupaten Pesawaran, mengukur kinerja rantai pasok keripik nangka pada Agroindustri Keripik Panda Alami, mengukur efisiensi rantai pasok pada Agroindustri Keripik Panda Alami, dan menghitung nilai 
tambah produk keripik nangka yang dihasilkan oleh Agroindustri Keripik Panda Alami.

\section{METODE PENELITIAN}

Penelitian dilakukan di agroindustri keripik Panda Alami yang berada di Desa Cipadang, Kecamatan Gedong Tataan, Kabupaten Pesawaran. Penentuan lokasi penelitian dilakukan secara sengaja purposive dengan pertimbangan daerah tersebut merupakan sentra produksi keripik nangka di Kabupaten Pesawaran dan adanya kerjasama mitra dengan beberapa petani serta terdapat permasalahan ketersediaan bahan baku nangka, antara jumlah permintaan dari agroindustri dengan jumlah bahan baku yang dipenuhi oleh petani mitra.

Pengambilan sampel untuk pelaku rantai pasok Agroindustri Keripik Panda Alami yang meliputi petani mitra, agroindustri, pedagang keripik, dan konsumen dilakukan dengan cara snowball yaitu dengan cara berantai untuk mengetahui keberadaan sampel lainnya (Nasution 2003). Responden penelitian ini sebanyak 1 orang pemilik agroindutri, 8 orang petani nangka, 12 pedagang keripik, dan 10 orang konsumen. Pengumpulan data dalam penelitian dilaksanakan pada bulan Februari 2017. Metode penelitian yang digunakan dalam penelitian ini adalah metode studi kasus pada Agroindustri Keripik Panda Alami di Desa Cipadang, Kecamatan Gedong Tataan, Kabupaten Pesawaran.

Penelitian ini dilakukan dengan menggunakan data primer dan data sekunder. Data primer diperoleh melalui wawancara langsung dengan responden terkait. Data sekunder diperoleh dari lembaga/instansi terkait seperti Badan Pusat Stastistik, Dinas Koperasi Perindustrian dan Perdagangan Kabupaten Pesawaran mengenai jumlah pelaku agroindstri, identitas agroindustri, dan pustaka lainnya yang berhubungan dengan penelitian ini.

Metode analisis data yang digunakan untuk mengidentifikasi sistem rantai pasok pada agroindustri keripik Panda Alami adalah metode deskriptif. Data yang telah terkumpul di analisis untuk mengetahui keadaan agroindustri keripik Panda Alami, mengidentifikasi rantai pasok Agroindustri Keripik Panda Alami, serta mengidentifikasi aktifitas yang dilakukan tiap pelaku dalam sistem rantai pasok Agroindustri Keripik Panda Alami. Metode ini merujuk pada penelitian Noviantari, Hasyim, dan Rosanti (2015).
Model rantai pasok yang terjadi di Agroindustri Panda Alami dibahas secara deskriptif dengan pengukuran kinerja rantai pasok yang dapat dilihat dari nilai-nilai pada setiap indikator Supply Chain Operation Refference yang merupakan model pengukuran kinerja yang dikeluarkan oleh Supply Chain Council pada tahun 2008 seperti yang dilakukan oleh Lestari, Abidin, dan Sadar (2016). Hasil pengukuran tersebut kemudian dibandingkan dengan nilai FoodSCOR card (Bolstroff 2011).

Pengukuran efisiensi rantai pasok dilakukan untuk mengetahui apakah rantai pasok nangka pada Agroindustri Keripik Panda Alami sudah efisien atau belum efisien. Pengolahan data untuk menentukan efisiensi rantai pasok pada penelitian ini menggunakan metode DEA (Data Envelopment Analysis) dengan menggunakan software bernama Deap 2.1. Perhitungan DEA pada penelitian ini dilakukan untuk mengukur tingkat efisiensi rantai pasok dengan menggunakan faktor input dan output. Analisis efisiensi rantai pasok nangka pada Agroindustri Keripik Panda Alami digunakan asumsi CSR (Constant Return to Scale).

Asumsi tersebut digunakan karena pengamatan dalam menganalisis rantai pasok nangka pada Agroindustri Keripik Panda Alami dilakukan pada satu periode waktu, sehingga perubahan faktor produksi diabaikan. Asumsi ini merujuk pada penelitian Budiarti (2017) yang mengunakan CSR pada pengukuran efisiensi. Model analisis yang digunakan pada penelitian ini sebagai berikut :

$\mathrm{Ef}=\frac{\sum_{\mathrm{r}}^{\mathrm{s}}=\mathrm{UrYr} 0}{\sum_{\mathrm{i}}^{\mathrm{m}}=\mathrm{ViXi} 0}$

Keterangan :

Ef : Efisiensi rantai pasok

$\mathrm{m}$ : Jumlah input

Ur : Bobot ouput ke-r

$\mathrm{Vi}$ : Bobot input ke-i

Xi0 : Nilai input ke-i yang digunakan oleh DMU (Decision Making Unit)

Yr0 : Nilai output ke-i yang digunakan oleh DMU

Berdasarkan pengolahan data pada indikatorindikator dalam persamaan linier yang telah disebutkan, maka dibuat kriteria sebagai berikut:

1. Jika $\mathrm{Ef}=1$, maka rantai pasok nangka pada Agroindustri Keripik Panda Alami sudah efisien.

2. Jika $\mathrm{Ef}<1$, maka rantai pasok Agroindustri Keripik Panda Alami belum efisien. 
Nilai tambah dihitung untuk mengetahui seberapa besar selisih harga antara buah nangka dengan keripik nangka yang dihasilkan agroindustri keripik Panda Alami. Selisih harga tersebut yang akan menambah pendapatan pelaku agroindustri keripik Panda Alami. Perhitungan nilai tambah menggunakan metode Hayami seperti yang dilakukan oleh Putri, Hasyim, dan Lestari (2016).

Kriteria nilai tambah adalah :

1. Jika NT >0, berarti pengembangan Agroindustri Keripik Panda Alami memberikan nilai tambah hasilnya positif.

2. Jika NT $<0, \quad$ berarti pengembangan Agroindustri Keripik Panda Alami tidak memberikan nilai tambah hasilnya negatif.

\section{HASIL DAN PEMBAHASAN}

\section{Keadaan Umum Responden}

Responden pada penelitian berjumlah 31 orang yang terdiri dari 8 orang petani, 1 orang pemilik agroindustri, 12 orang pedagang keripik dan 10 orang konsumen. Usia responden pelaku agroindustri keripik nangka di Agroindustri Keripik Panda Alami termasuk dalam golongan usia produktif, sehingga cukup potensial untuk melakukan kegiatan pada Agroindustri Keripik Panda Alami. Tingkat pendidikan responden petani masih tergolong rendah. Pengalaman usaha yang dimiliki oleh responden petani, pemilik agroindustri, dan pedagang dapat dikatakan cukup terampil, karena rata-rata responden memiliki pengalaman usaha lebih dari 10 tahun. Jumlah tanggungan keluarga responden petani, pemilik agroindustri, dan pedagang pada penelitian ini cukup beragam yaitu $2-6$ orang.

\section{Analisis Pola Aliran Rantai Pasok}

Aliran pelaku rantai pasok komoditas nangka pada Agroindustri Keripik Panda Alami terdiri atas petani, Agroindustri Keripik Panda Alami, pedagang keripik dan konsumen. Aliran komoditas tersebut dimulai dari petani sebagai pemasok utama bahan baku. Sistem komunikasi yang terjalin dalam pengorganisasian bahan baku sudah terintegrasi dengan baik antar anggota dalam rantai pasok. Aliran informasi dari agroindustri ke petani berhubungan dengan informasi terkait kapasitas bahan baku dan waktu pengiriman. Pola rantai pasok ini merujuk pada penelitian Sari (2012) tentang rantai pasok tahu tempe, bahwa pola rantai pasok dimulai dari petani sebagai pemasok utama. Pola rantai pasok keripik nangka pada Agroindustri Keripik Panda Alami dapat dilihat pada Gambar 1.

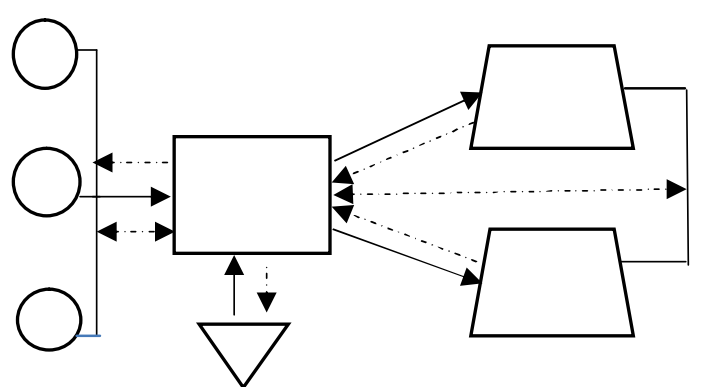

Gambar 1. Pola aliran rantai pasok pada agroindustri panda alami

Keterangan :

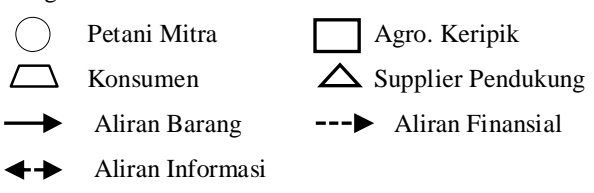

Kinerja Rantai Pasok

Hasil pengukuran kinerja rantai pasok menunjukkan bahwa kinerja petani sudah baik berdasarkan indikator pengiriman, pemenuhan pesanan bahan baku dan kesesuaian, karena telah mencapai target nilai yang telah ditetapkan pada indikator foodSCOR card. Indikator cash to cash cycle time petani atau waktu tunggu pembayaran petani dari agroindustri menunjukkan adanya waktu tunggu selama tujuh hari, akan tetapi cash to cash cycle time petani masih masuk ke dalam kategori baik. Pengukuran kinerja pada Agroindustri Keripik Panda Alami menunjukkan bahwa kinerja agroindustri sudah baik berdasarkan kinerja pemenuhan pesanan, waktu pengiriman, kesesuaian dengan standar dan persediaan harian, karena telah mencapai target nilai yang telah ditetapkan oleh foodSCOR card. Artinya tujuan akhir agroindustri sudah tercapai. Rekapitulasi nilai kinerja rantai pasok pasok tingkat petani dan agroindustri dapat dilihat pada Tabel 1 . 
Tabel 1. Rekapitulasi nilai dan kriteria kinerja petani dan agroindustri.

\begin{tabular}{|c|c|c|c|c|c|}
\hline \multirow{2}{*}{ Indikator } & \multirow{2}{*}{$\begin{array}{c}\text { Target untuk Mencapai } \\
\text { Kriteria Baik }\end{array}$} & \multicolumn{2}{|c|}{ Petani Mitra } & \multicolumn{2}{|c|}{ Panda Alami } \\
\hline & & Nilai & Kriteria & Nilai & Kriteria \\
\hline Lead Time Pemenuhan Pesanan (jam) & $\leq 72$ & 4,12 & Baik & 62,40 & Baik \\
\hline Siklus Pemenuhan Pesanan (jam) & $\leq 336$ & 2,44 & Baik & 59,00 & Baik \\
\hline Fleksibilitas Rantai Pasok (jam) & $\leq 240$ & 0,00 & Baik & 0,00 & Baik \\
\hline Cash to Cash Cycle Time (hari) & $\leq 29$ & 7,00 & Baik & 0,00 & Baik \\
\hline Persediaan Harian (hari) & $\leq 23$ & 0,00 & Baik & 21,00 & Baik \\
\hline Kinerja Pengiriman (\%) & $\geq 95$ & 98,00 & Baik & 100,00 & Baik \\
\hline Pemenuhan Pesanan $(\%)$ & $\geq 88$ & 94,29 & Baik & 100,00 & Baik \\
\hline Kesesuaian dengan Standar (\%) & $\geq 99$ & 95,12 & Baik & 100,00 & Baik \\
\hline
\end{tabular}

Terlihat pada Tabel 1, rekapitulasi nilai kinerja pada tingkat petani dan agroindustri secara keseluruhan telah mencapai target nilai yang ditetapkan pada FoodSCOR card. Nilai kinerja petani dan agroindustri pada indikator kinerja pengiriman, pemenuhan pesanan, dan kesesuaian dengan standar adalah 100 persen. Hasil pengukuran kinerja ini sejalan dengan penelitian Yolandika (2016) mengenai pengukuran kinerja rantai pasok brokoli bahwa pengukuran indikator pengiriman dan pemenuhan pesanan sesuai dengan standar foodSCOR card.

\section{Efisiensi Rantai Pasok}

\section{a. Efisiensi Rantai Pasok Nangka Tingkat Pemasok}

Pengukuran efisiensi rantai pasok dilakukan dengan menggunakan metode Data Envelopment Analysis (DEA), melibatkan delapan orang petani nangka sebagai DMU. Hasil pengukuran menunjukkan bahwa dari delapan pemasok bahan baku hanya terdapat 3 petani memiliki nilai efisiensi $\mathrm{Ef}=1$, artinya tiga pemasok tersebut sudah efisien, petani tersebut dikatakan efisien apabila faktor input dan output petani sudah tepat. Terdapat lima pemasok lainnya yang memiliki nilai $\mathrm{Ef}<1$, artinya lima pemasok nangka pada Agroindustri Keripik Panda Alami belum efisien, DMU yang belum efisien dapat mencapai tingkat efisiensi apabila ditinjau nilai input slack dan output slack.

Input slack adalah besarnya input yang dapat dikurangi agar DMU yang belum efisien dapat mencapai tingkat efisiensi. Output slack adalah besarnya output yang dapat ditingkatkan agar DMU yang belum efisien dapat mencapai tingkat efisiensinya. Berdasarkan hasil perhitungan yang telah dilakukan menunjukkan bahwa pada DMU yang belum efisien memiliki nilai input slack pada input X1 (biaya pemetikan). Selanjutnya, untuk meningkatkan efisiensi, petani juga harus meningkatkan penerimaan yang dilihat dari output slack. Pada DMU yang belum efisien memiliki nilai output slack pada output Y2 (penerimaan). Strategi untuk meningkatkan penerimaan yang dapat dilakukan yaitu dengan cara menaikkan harga jual output, namun dengan kemungkinan yang sangat kecil, karena peluang pasar yang masih rendah.

\section{b. Efisiensi Rantai Pasok Nangka Tingkat Agroindustri}

Analisis efisiensi rantai pasok pada tingkat Agroindustri hanya melibatkan Agroindustri Keripik Panda Alami sebagai DMU. Nilai efisiensi rantai pasok nangka pada tingkat agroindustri $\mathrm{Ef}=1$, artinya Agroindustri Keripik Panda Alami sudah efisien. Agroindustri Keripik Panda Alami dikatakan efisien artinya faktor input dan output pada agroindustri sudah tepat.

\section{c. Efisiensi Rantai Pasok Nangka Tingkat Retail}

Analisis efisiensi rantai pasok pada tingkat retail atau pedagang keripik nangka melibatkan 12 orang pedagang keripik sebagai DMU. Nilai efisiensi rantai pasok nangka pada tingkat retail menunjukkan seluruh DMU atau retail pada Agroindustri Keripik Panda Alami sebesar Ef $=1$, artinya seluruh pedagang keripik nangka telah efisien secara teknis. Retail yang terlibat pada sistem rantai pasok Agroindustri Keripik Panda Alami efisien artinya faktor input dan output pada retail sudah tepat. Nilai efisiensi seluruh DMU rantai pasok pada Agroindustri Keripik Panda Alami dapat dilihat pada Tabel 2.

Tabel 2. Nilai efisiensi seluruh DMU

\begin{tabular}{lrrr}
\hline Nama & $\begin{array}{c}\text { Jumlah } \\
\text { DMU }\end{array}$ & $\begin{array}{c}\text { Jumlah } \\
\text { DMU } \\
\text { efisien }\end{array}$ & $\begin{array}{c}\text { Persentase } \\
(\%)\end{array}$ \\
\hline Petani & 8 & 3 & 18,75 \\
Agroindustri & 1 & 1 & 6,25 \\
Retail & 12 & 12 & 75,00 \\
\hline
\end{tabular}




\section{Analisis Nilai Tambah}

a. Nilai Tambah Keripik Nangka dengan Penggorengan mesin vakum

Nilai faktor konversi yang diperoleh sebesar 0,20 yang artinya dari 1 kilogram buah nangka menghasilkan 0,20 kilogram keripik nangka. Sumbangan input lain yang paling besar pada pengolahan keripik nangka yaitu dari penggunaan minyak goreng sebesar $64,73 \%$ dan solar sebesar $22,54 \%$. Nilai tambah yang diperoleh dari pengolahan satu kilogram buah nangka menjadi keripik nangka rata-rata sebesar Rp6.428.

Keuntungan yang diperoleh dari proses pengolahan bahan baku buah nangka menjadi keripik nangka sebesar Rp5.156 dengan tingkat keuntungan sebesar $80,20 \%$ dari nilai produk. Nilai keuntungan tersebut merupakan selisih dari nilai tambah dengan imbalan tenaga kerja. Nilai keuntungan yang diperoleh dari kegiatan pengolahan ini cukup tinggi. Hal ini berarti agroindustri keripik nangka dalam aktifitasnya sudah berorientasi pada pencapaian tingkat keuntungan tertentu.

Nilai tambah produk keripik nangka dengan penggorengan mesin vakum pada Agroindustri Keripik Panda Alami menunjukkan nilai tambah positif, artinya usaha pengolahan keripik nangka memberikan nilai tambah positif dan layak untuk dikembangkan. Usaha pengolahan keripik nangka pada Agroindustri Keripik Panda Alami masuk dalam agroindustri padat modal, karena nilai balas jasa pemilik faktor produksi lebih tinggi pada keuntungan dibandingkan dengan tenaga kerja. Artinya, agroindustri tersebut menggunakan modal yang besar sehingga teknologi yang digunakan modern.

Hasil penelitian ini sejalan dengan penelitian Nurmedika (2013), mengenai analisis nilai tambah keripik nangka pada agroindustri rumah tangga tiara di Kota Palu. Hasil penelitian tersebut menunjukkan bahwa agroindustri pengolahan keripik nangka bersifat padat modal, dilihat dari balas jasa faktor produksi lebih besar keuntungan dibandingkan dengan pendapatan tenaga kerja. Berikut ini merupakan perhitungan nilai tambah Keripik Panda Alami dapat dilihat pada Tabel 3.

Hasil perhitungan dan penelitian yang telah dilakukan pada Agroindustri Keripik Panda Alami menunjukkan bahwa pengolahan keripik nangka dengan penggorengan dengan mesin memberikan nilai tambah yang positif, artinya usaha pengolahan keripik nangka layak untuk dikembangkan.

Tabel 3. Nilai tambah keripik nangka dengan proses penggorengan mesin vakum (oven)

\begin{tabular}{|c|c|c|c|}
\hline No & $\begin{array}{c}\text { Variabel } \\
\text { Output, Input dan Harga } \\
\end{array}$ & Nilai & Oven \\
\hline 1 & Output (kg/bulan) & A & $1.495,00$ \\
\hline 2 & Bahan baku(kg/bulan) & $\mathrm{B}$ & $7.475,00$ \\
\hline 3 & Tenaga Kerja (HOK/bulan) & $\mathrm{C}$ & 216,00 \\
\hline 4 & Faktor Konversi & $\mathrm{D}=\mathrm{A} / \mathrm{B}$ & 0,20 \\
\hline 5 & Koefisien Tenaga Kerja & $\mathrm{E}=\mathrm{C} / \mathrm{B}$ & 0,03 \\
\hline 6 & Harga Output (Rp) & $\mathrm{F}$ & $100.000,00$ \\
\hline 7 & Upah Rata-rata Tenaga Kerja (Rp/HOK) & $\mathrm{G}$ & $44.000,00$ \\
\hline \multicolumn{4}{|c|}{ Pendapatan dan Keuntungan } \\
\hline 8 & Harga bahan baku $(\mathrm{Rp} / \mathrm{Kg})$ & $\mathrm{H}$ & $2.000,00$ \\
\hline 9 & Sumbangan input lain $(\mathrm{Rp} / \mathrm{Kg})$ & I & $11.572,00$ \\
\hline \multirow{7}{*}{10} & Nilai Output & $\mathrm{J}=\mathrm{D} \times \mathrm{F}$ & $20.000,00$ \\
\hline & a. Nilai Tambah $(\mathrm{Rp} / \mathrm{Kg})$ & $\mathrm{K}=\mathrm{J}-\mathrm{I}-\mathrm{H}$ & $6.428,00$ \\
\hline & b. Rasio Nilai Tambah & $\mathrm{L}=(\mathrm{K} / \mathrm{J}) \times 100 \%$ & 32,14 \\
\hline & a. Imbalan Tenaga Kerja (Rp/Kg) & $M=E \times G$ & $1.271,00$ \\
\hline & b. Bagian Tenaga Kerja & $N=(M / K) \times 100(\%)$ & 19,80 \\
\hline & a. Keuntungan (Rp/Kg) & $\mathrm{O}=\mathrm{K}-\mathrm{M}$ & $5.156,00$ \\
\hline & b. Tingkat Keuntungan & $\mathrm{P}=\mathrm{O} / \mathrm{K} \times 100(\%)$ & 80,20 \\
\hline \multicolumn{4}{|c|}{ Balas Jasa Pemilik Faktor - Faktor Produksi } \\
\hline 11 & Margin Keuntungan & $\mathrm{Q}=\mathrm{J}-\mathrm{H}$ & $18.000,00$ \\
\hline \multirow{2}{*}{12} & a. Keuntungan & $\mathrm{R}=\mathrm{O} / \mathrm{Q} \times 100 \%$ & 28,60 \\
\hline & b. Tenaga Kerja & $\mathrm{S}=\mathrm{M} / \mathrm{Q} \times 100 \%$ & 7,10 \\
\hline 13 & c. Input Lain & $\mathrm{T}=\mathrm{I} / \mathrm{Q} \times 100 \%$ & 64,30 \\
\hline
\end{tabular}




\section{KESIMPULAN}

Kesimpulan dari penelitian adalah pola aliran rantai pasok pada Agroindustri Keripik Panda Alami dimulai dari petani sebagai pemasok utama bahan baku, Agroindustri Keripik Panda Alami, pedagang keripik, dan konsumen. Kinerja rantai pasok nangka pada Agroindustri Keripik Panda Alami memiliki kriteria yang baik berdasarkan pengukuran indikator input dan output dengan kriteria foodSCOR card pada setiap anggota rantai pasok. Pengukuran efisiensi rantai pasok menunjukkan hanya 37,50\% pelaku rantai pasok Agroindustri Keripik Panda Alami yang sudah efisien secara teknis untuk kategori DMU petani, dan $100,00 \%$ efisien untuk kategori DMU retail dan DMU pedagang. Secara keseluruhan, sistem rantai pasok pada Agroindustri Keripik Panda Alami belum dapat memberikan pembagian manfaat yang adil, karena masih ada pihak - pihak yang belum efisien. Nilai tambah yang diperoleh dari keripik nangka dengan penggorengan mesin vakum memiliki nilai tambah yang positif dan layak untuk diusahakan.

\section{DAFTAR PUSTAKA}

Arikunto S. 2004. Prosedur Penelitian Suatu Pendekatan Praktik. Rineka Cipta. Bandung.

Bolstorff P dan Rosenbaum R. 2011. Supply Chain Excellence: A Handbook for Dramatic Improvement Using the SCOR Model. New York (US): AMACOM. (US). Prentice Hall. National Quality Program Gaithersburg. USA.

Budiarti A. 2017. Analisis rantai pasok dan harga pokok penjualan daging ayam broiler pada rumah potong ayam bersertifikat di Provinsi
Lampung. Skripsi. Universitas Lampung. Lampung.

Nasution. 2003. Metode Research, Penelitian Ilmiah. Tesis. Bandung.

Lestari, Abidin Z, dan Sadar S. 2016. Analisis kinerja rantai pasok dan nilai tambah produk olahan Kelompok Wanita Tani Melati di Desa Tribudisyukur Kecamatan Kebun Tebu Lampung Barat. JIIA, 4 (1) : 98-104. http:// jurnal.fp.unila.ac.id/index.php/JIA/article/vie w/235/234. [5 Mei 2017].

Noviantari, Hasyim AI, dan Rosanti N. 2015. Analisis rantai pasok dan nilai tambah agroindustri kopi luwak di Provinsi Lampung. JIIA, 3 (1) : 78-103. http://jurnal.fp.unila.ac. id/index.php/JIA/article/view/1500/1354 . [16 Januari 2015].

Nurmedika A. 2013. Pendapatan dan nilai tambah keripik nangka pada industri rumah tangga tiara di Kota Palu. Skripsi. Universitas Tadukalo. Palu.

Putri IT, Hasyim AI, dan Lestari DAH. 2016. Nilai tambah, bauran pemasaran (marketing mix) dan perilaku konsumen dalam pengambilan keputusan pembelian produk rotan (kursi teras tanggok dan kursi teras pengki) di Kota Bandar Lampung. JIIA, 4 (1) : 68-99. http://jurnal.fp.unila.ac.id/index.php/ JIA /article/view/299/354 [17 Januari 2016].

Sari E. 2012. Pola Aliran Rantai Pasok, Pengendalian Persediaan Bahan Baku dan Strategi Peningkatan Kinerja Agroindustri Tahu Tempe di Kelurahan Gunung Sulah Kecamatan Sukarame Bandar Lampung. Skripsi. Universitas Lampung. Lampung.

Yolandika C. 2016. Analisis Supply Chain Management Brokoli di Kecamatan Lembang Kabupaten Bandung Barat. Tesis. Institut Pertanian Bogor. Bogor. 